\title{
INTRODUÇÃO À EDIÇÃO ESPECIAL CIÊNCIA E VALORES: A INTERAÇÃO ENTRE CIÊNCIA, TECNOLOGIA E SOCIEDADE
}

\author{
INTRODUCTION TO THE SPECIAL ISSUE \\ SCIENCE AND VALUES: THE INTERACTION OF SCIENCE, TECHNOLOGY, AND SOCIETY \\ DÉBORA AYMORÉ \\ Universidade do Estado do Amapá, Universidade Federal do Paraná, BRASIL \\ deboraaymore@gmail.com \\ IVAN FERREIRA DA CUNHA \\ Universidade Federal de Santa Catarina, BRASIL \\ ivan.fc@ufsc.br
}

RECEIVED: 01/09/2021

ACCEPTED: 16/09/2021

Produzir um número especial em um periódico internacional de prestígio tal como Principia, vinculado ao Núcleo de Epistemologia e Lógica da Universidade Federal de Santa Catarina (NEL/UFSC), é sempre uma aventura. E, como em toda jornada, nada mais revigorante do que contar com uma série de pessoas que, com as suas respectivas formações e habilidades, contribuem para o sucesso da empreitada.

Esta jornada, no entanto, iniciou-se no segundo semestre de 2019 no ADC-19, ou seja, antes da declaração da pandemia Covid-19, quando os professores Ivan Ferreira da Cunha (UFSC) e Hugh Lacey (Swarthmore College, EUA), aceitaram convites para ministrar conferências na Universidade Federal do Paraná (UFPR). Essas conferências foram realizadas atendendo ao chamado à aventura do IV Ciclo de Conferências do NECTEC - Núcleo de Estudos da Cultura Técnica e Científica, sediado no Departamento de Filosofia daquela instituição, sob a coordenação do professor Dr. Ronei Clécio Mocellin.

O primeiro semestre de 2020, em pleno DDC-19 (depois da declaração da pandemia Covid-19) foi um período bastante atribulado, em que a sociedade como um todo se adaptava às exigências de isolamento social devido ao coronavírus. Nesse período, em que as universidades também se adaptavam o mais rapidamente possível aos sistemas e práticas próprias do modelo remoto de ensino, foi lançada a chamada de artigos para esta edição especial. Os textos foram recebidos e avaliados no primeiro semestre de 2021, período em que a pandemia ultrapassou no Brasil o lamentável número de 500 mil óbitos em junho de 2021, de acordo com o Boletim do Observatório Covid-19 Fiocruz, de 25 de junho de 2021. 
Dentre tantas crises, sanitária, econômica, ambiental e, sobretudo, humana, a jornada empreendida até a publicação deste número especial sobre Ciência e Valores foi conduzida com o apoio do editor da revista Principia, professor Ivan, a quem agradeço pela oportunidade de aprendizado nesta atividade acadêmica realizada em condições tão peculiares.

Quanto ao conteúdo, é preciso mencionar que os nossos próprios professores e orientadores, a saber, Alberto Cupani (UFSC), Pablo Rubén Mariconda (USP) e Hugh Lacey, estiveram direta e indiretamente envolvidos na condução do número especial. Diretamente por serem eles, antes de nós, que fomentaram, por intermédio da docência, da publicação de textos originais e das palestras ministradas, a relação de interação recíproca entre a ciência e os valores em território brasileiro, mantendo, inclusive, o vínculo com o debate acadêmico internacional. Indiretamente, tais professores estiveram igualmente envolvidos, devido ao aprendizado que nos proporcionaram (e ainda proporcionam) enquanto autores e editores, de suas próprias obras ou dos originais a eles encaminhados no incansável desempenho das funções de editores de revistas e de livros acadêmicos de repercussão bastante significativa.

Toda a formação acadêmica recebida a partir do trabalho contínuo destes professores repercutiu, no mês de agosto de 2021, em um Workshop no $12^{\circ}$ Simpósio Internacional Principia dedicado ao tema de Ciência e Valores. Nesse Workshop foi possível apresentar uma amostra das discussões que nossa comunidade desenvolve acerca do tema. E esta edição especial apresenta uma amostra um pouco mais ampliada. Ressalta-se: houve muito trabalho e pesquisa prévia para que estes dois momentos fossem possíveis, tanto em relação ao evento realizado por meios virtuais, quanto à publicação do número especial sobre Ciência e Valores na revista Principia.

Em se tratando dos nossos tempos pandêmicos, que estendem o período DDC-19 até a publicação deste número especial, os editores consideram relevante fomentar a reflexão sobre as relações de reforço mútuo entre as práticas científicas e técnicas, em sua contínua interação com as sociedades. Se a ciência não é livre de valores, é preciso identificar os valores que interagem com as ciências e técnicas, o modo como os valores interagem e em que momento das práticas científicas e aplicações: seria na avaliação das teorias e das hipóteses científicas? Na difusão dos resultados por meio dos periódicos? Na aplicação técnica do conhecimento teórico e prático metodológica e empiricamente obtidos?

Mesmo com a ativação da reflexão a partir da formulação de questões objetivas como essas, o fato é que as respostas obtidas são diferentes. Isso se dá em parte por motivos relacionados ao próprio objeto investigado, tais como a complexidade e a variabilidade das ciências e das técnicas, relacionados à riqueza dos modelos históricoepistemológicos disponíveis na filosofia, na história e na sociologia das ciências e técnicas. E também igualmente devido à sensibilidade própria de cada pesquisador e pesquisadora que se aventura na investigação sobre a ciência e os valores. 
Evidentemente que, para todos que empreendem tais pesquisas, a valorização da sociedade é mantida no horizonte das preocupações compartilhadas. Pois, se em um dos polos da investigação encontramos as ciências, as técnicas e os valores, no outro polo estará sempre esta valorização das sociedades, cujos membros não são apenas destinatários passivos de aplicações técnicas, tais como as vacinas, as sementes geneticamente modificadas ou tradicionalmente selecionadas, ou ainda dos softwares e hardwares utilizados, entre outros, para viabilizar concretamente este tipo de produção acadêmica que, caso contrário, permaneceria enquanto projeto ou ideia.

A pandemia Covid-19 nos trouxe muito mais do que o desafio de nos familiarizarmos com o ensino remoto, com os seus instrumentos, as suas técnicas pedagógicas. Pois, no centro da preocupação de todos nós esteve (e ainda está) a saúde, a vida dignamente vivida por meio do trabalho em um ambiente saudável para a atual e as futuras gerações. Quando estamos saudáveis, nós pressupomos a saúde como dada, no silêncio dos órgãos. E, no entanto, a pandemia Covid-19 nos colocou a todos em estado de atenção, assim como deslocou significativamente o eixo da pesquisa científica. Deste modo, podemos nos perguntar: qual o papel da filosofia neste particular? $\mathrm{Ou}$, mais amplamente, qual o papel das humanidades?

O nosso papel enquanto pesquisadores e pesquisadoras ativos das humanidades é, certamente, diferente daquele dos profissionais da área da saúde e da biomedicina, biotecnologia, entre tantos outros. Nós, em filosofia, buscamos um entendimento profundo da complexidade das práticas sociais, por meio do estudo e da pesquisa da forma como se expressam os valores, quer por meio das palavras e dos discursos, quer por meio das ações realizadas individual e socialmente.

Não se trata de afirmar que nos dedicamos exclusivamente a esta tarefa, ao contrário. Igualmente engajados neste esforço intergeracional de investigação estão historiadores, sociólogos, engenheiros, cientistas, técnicos, bem como os saberes tradicionais e as epistemologias plurais (feministas, decoloniais, do sul etc.), por vezes não enfatizados no ambiente acadêmico, mas de onde provêm alternativas e vivências no mundo que colaboram para o enriquecimento constante do mundo acadêmico.

Assim, se a saúde se destacou como valor social de alta estima desde a declaração da pandemia, também podemos ressaltar outros valores que se reaproximaram dela, como é o caso da moradia digna, da alimentação nutritiva, do trabalho como fonte de renda e sustento, do desenvolvimento sustentável, entendido como etapa prévia para a formação de relação mais equilibrada com a natureza. Todos estes fatores estão relacionados, direta ou indiretamente, com a saúde, com as pesquisas científicas e aplicações tecnológicas em nossas sociedades contemporâneas. Pesquisas estas que se mostram cada vez mais conscientes do necessário engajamento, atentas às necessidades sociais e à emergência de novas sensibilidades, como no caso da saúde compreendida amplamente como biopsicossocial.

Se a pandemia Covid-19 nos suscita a reflexão sobre o "novo normal", as humani- 
dades aproximam-se das práticas científicas e aplicações técnicas também como uma forma de relembrar o que há de humano nas atividades científica e tecnologicamente orientadas. Dentre os elementos de humanização, podemos destacar que:

- existem pessoas que realizam as práticas científicas e tecnológicas;

- existem pessoas que, não sendo cientistas ou técnicos, almejam certos resultados que ampliem o seu bem-estar, a sua saúde, a sua qualidade de vida, a solidariedade comunitária e o equilíbrio ambiental;

- existem instituições formadas também por pessoas, que viram as suas vidas ameaçadas por um vírus.

Como não supor que as ciências e os valores interagem, se as pessoas que carregam consigo os mais variados valores estão sempre presentes, quer quando praticam as ciências, quer quando estão silenciosamente a espera de seus resultados?

Cientistas, e também engenheiros, técnicos, produzem conhecimentos e práticas orientadas por uma forma de pesquisa sistemática, fundada em métodos e baseadas na empiria, ou seja, no conhecimento do mundo, da natureza, das entidades que o habitam. Assim, os valores estão mais próximos do que poderíamos inicialmente supor das práticas científicas e das aplicações técnicas, pois elas são realizadas por seres humanos e tendo como destinatários seres humanos e não humanos, como os animais, as plantas etc.

Por isso, que este tempo tão gentilmente cedido na grade de atividades síncronas do evento Principia, e este espaço-tempo concedido pelo número especial Ciência e Valores na revista Principia nos relembre isto: que ciência e técnica são e continuarão sendo tão humanas quanto os seus praticantes e os seus destinatários almejarem. Como busca por conhecimento engajado com a melhoria da saúde, com o meio ambiente equilibrado, com a vida de todos.

No que tange ao conteúdo deste número especial sobre Ciência e Valores da revista Principia, cabe-nos apresentar as contribuições recebidas e pacientemente revisadas pelas autoras e pelos autores.

No artigo "Ciencia y valores, otra vez", o professor Alberto Cupani nos apresenta uma análise socialmente engajada da obra de Matthew J. Brown identificando, por um lado, a necessidade de abandono da tese da ciência livre de valores e, por outro lado, a possibilidade de valores não epistêmicos representarem papeis relevantes na constituição da racionalidade científica.

No artigo "Valores na ciência: devemos dar adeus à imparcialidade?", Claudio Ricardo Martins dos Reis nos apresenta a riqueza dos estudos sobre a interação entre as atividades científicas e os valores, e, em defesa da abordagem de Hugh Lacey, considera que a imparcialidade pode ser mantida como ideal regulador na aceitação das teorias científicas. Além disso, em suas práticas, as ciências expressam valores 
não cognitivos, mas estes podem ser, ainda assim, compatíveis com a racionalidade científica.

Em "O papel dos valores na pesquisa em Agroecologia", Gabriel Bianconi Fernandes identifica, a partir de pesquisa situada no Brasil, a possibilidade de adesão satisfatória à agroecologia, como prática sensível aos contextos sociais e ambientais, o que contribui para a visualização de alternativas para a constituição de práticas sociais que beneficiem a soberania alimentar.

Em "Chemistry, Society, and Uncertainty", os professores Ronei Clécio Mocellin e Luciana Zaterka praticam uma guinada materialista nos estudos da ciência e da técnica, analisando casos específicos do uso de substâncias químicas no ambiente e na sociedade, o que suscita reflexões sobre as consequências da imprevisibilidade dessas substâncias.

Em "Biological Identity and 'Restitution' in Argentina", Mariana Córdoba, María José Ferreira Ruiz \& Fiorela Alassia tratam das relações entre a ciência, as técnicas de identificação de parentesco genético na disputa sobre a restituição de crianças realizada pela organização das "Abuelas de la Plaza de Mayo", ao elegerem como questão central a tensão entre identidade pessoal e biológica.

Em "Agnotologia e o Princípio da Precaução", Pedro Bravo de Souza aborda a questão da constituição deliberada de ignorância por grupos específicos o que, por sua vez, pode afetar a credibilidade das pesquisas científicas tais como as que consolidaram a emergência do princípio jurídico de precaução na década de 1970.

No artigo "Negacionistas são os outros? Verdade, engano e interesse na era da pós-verdade", a reflexão central da professora Alyne de Castro Costa é a consideração da dupla medida de validação epistêmica, em que ao afirmar determinado discurso como negacionista ele se constitui como ilegítimo enquanto o discurso próprio se legitima. No entanto, segundo a autora, quanto mais se expressa o enganar e o enganar-se, tanto mais condenável é o discurso negacionista, a exemplo do negacionista climático, abordado por Bruno Latour.

Em "La integración entre ciencia, opinión pública y democracia", Livio Mattarollo aborda a crítica da tese da ciência livre de valores, considerando seu contexto histórico de surgimento na Guerra Fria e na reformulação posterior da distinção entre o contexto de descoberta e de justificação nas ciências na década de 1980. Porém, em conformidade com Heather Douglas, os ideais de neutralidade, imparcialidade e autonomia não seriam nem alcançáveis e nem sustentáveis pela prática científica. Além disso, a partir de John Dewey, o autor reafirma a relevância da democracia mesmo na produção da pesquisa científica.

Finalmente, a resenha escrita por Félix Flores Pinheiro retoma a reflexão de Alberto Cupani, o autor do artigo que inicia este número especial, permitindo-nos conhecer a obra Sobre a ciência: estudos de filosofia da ciência (2018). No livro de Cupani, como Pinheiro nos mostra, a ciência é analisada a partir de suas práticas e tal 
como as valorizamos, seja em termos técnicos ou teóricos, à medida que sua função social é caracterizada em função da melhoria das condições de vida ambiental e socialmente compartilhadas, o que, inclusive, reforça a possibilidade de manterem-se laços de confiança que as pessoas identificam com as práticas científicas.

Para concluir este breve relato de uma jornada até a publicação da edição especial "Ciência e Valores: a interação entre ciência, tecnologia e sociedade", devemos agradecer aos autores e autoras que apresentaram contribuições, aprovadas ou não, a esta edição especial, bem como aos pareceristas anônimos que nos ajudaram a avaliar os textos.

Boa leitura! 